\title{
Recording strategies and selection potential of feed intake measured using the $X$-ray method in rainbow trout
}

\author{
Antti KAUSE $^{\mathrm{a} *}$, Declan ToBIN ${ }^{\mathrm{b}}$, Alexandre DoBLY $^{\mathrm{b} * *}$, \\ Dominic Houlihan ${ }^{\mathrm{b}}$, Sam MARTIN ${ }^{\mathrm{b}}$, Esa A. MÄNTYSAARI ${ }^{\mathrm{a}}$, \\ Ossi RITOLA $^{\mathrm{c}}$, Kari RUOHONEN ${ }^{\mathrm{d}}$ \\ ${ }^{a}$ MTT Agrifood Research Finland, Animal Production Research, Animal Breeding, \\ FIN-31600 Jokioinen, Finland \\ ${ }^{\mathrm{b}}$ School of Biological Sciences, Department of Zoology, University of Aberdeen, Aberdeen, \\ AB24 2TZ, United Kingdom \\ ${ }^{\mathrm{c}}$ Finnish Game and Fisheries Research Institute, Tervo Fisheries Research and Aquaculture, \\ FIN-72210 Tervo, Finland \\ ${ }^{\mathrm{d}}$ Finnish Game and Fisheries Research Institute, Turku Game and Fisheries Research, \\ FIN-20520 Turku, Finland
}

(Received 4 November 2005; accepted 27 March 2006)

\begin{abstract}
This study examines the way long-term feed intake should be recorded accurately for selective breeding purposes, and estimates selection potential in feed intake using the Xray method to record individual daily feed intake in rainbow trout (Oncorhynchus mykiss). The analysis showed that the point estimates of daily feed intake displayed low repeatabilities $(r=0.09-0.32)$. This indicates that a minimum of three repeated records were needed to accurately record average feed intake at a fixed age. To effectively breed for feed intake over the whole growing period, it is necessary to determine average feed intake at different ages, since there were only moderate phenotypic and genetic correlations between average daily feed intake recorded at $140 \mathrm{~g}, 750 \mathrm{~g}$ and $2000 \mathrm{~g}$ wet mass. Heritability for average daily feed intake was low (average $h^{2}=0.10$ ), indicating that modest genetic changes can be obtained in response to selection. It was concluded that selection to genetically change long-term feed intake can be successful, yet repeated observations at several life stages are needed to ensure the accuracy of feed intake estimates and the efficiency of selection.
\end{abstract}

feed efficiency / X-radiography / heritability / repeatability / salmonids

\footnotetext{
* Corresponding author: Antti.Kause@mtt.fi

** Current address: Unit of Social Ecology, Université Libre de Bruxelles, CP 231, Bd du Triomphe, 1050, Belgium.
} 


\section{INTRODUCTION}

Feed is one of the major costs in farm animal production. In aquaculture, improving feed efficiency, a ratio of wet mass gain to feed intake, would have the effect of reducing feed costs and minimising environmental loading. Selective breeding is a potential tool for improving feed efficiency. Feed efficiency can be improved by simultaneous selection for rapid growth and against feed intake, or, when growth rate and feed efficiency are favourably genetically correlated, by sole selection for increased growth rate [21]. Since feed intake is a fundamental component of feed efficiency, reliable means of recording feed intake are required. This study examined the way long-term feed intake should be recorded in rainbow trout (Oncorhynchus mykiss Walbaum) for selective breeding purposes, and estimated selection potential in feed intake.

In order to be able to estimate the genetic potential for selection, individual feed intake needs to be recorded in a family-structured population. For three reasons, an accurate recording of individual feed intake over the whole growing period is challenging in groups of fish. First, feed intake of individuals varies greatly from day-to-day in salmonids e.g. [15, 28]. The observed high variability reduces the ability to predict long-term feed intake of an individual using a single daily record [16]. Because it is known that measurement accuracy can be increased by recording the same individuals repeatedly [9], it is of interest to quantify the number of repeated daily feed intake records needed at each fixed age point to accurately estimate average feed intake. Second, individual ranking across ages may change. For breeding purposes, it is of interest to know whether or not early feed intake measurements can be used as reliable genetic predictors over the whole growing period. It would be tempting to measure feed intake from young fish because feed intake is especially laborious to record from large fish but validation of this method is required. So far, estimates for genetic correlations between feed intake recorded at different stages of the life cycle have not been available for any fish species. Third, recording individual feed intake on a large number of fish held in a common tank is technically difficult.

A point estimate of individual feed intake from a large number of fish can be recorded by the X-ray method $[14,16,17,30]$. To measure feed intake using the X-ray method, all fish held in a tank are first fed with feed containing small glass beads containing lead oxide. Thereafter, the fish are X-rayed. The number of glass beads consumed can be counted from the X-ray films. Because the glass bead content of the feed is known, it is possible to calculate the quantity of feed that each fish consumed $[16,30]$. The question remains, however, 
whether the X-ray method would suffice for selection purposes that are aimed at changing long-term feed intake lasting over the whole on-growing period.

The X-ray method was applied here for a large number of pedigreed rainbow trout Oncorhynchus mykiss (Walbaum) to examine the following four topics. First, it was assessed how many daily feed intake measurements are needed to accurately estimate average feed intake of an individual at a fixed age. Second, it was tested whether feed intake displays non-zero heritabilities that would allow its genetic improvement through selection. Third, to study whether recording of feed intake at a single age can be used as a predictor over the whole growing period up to $2 \mathrm{~kg}$ fish, it was assessed whether average feed intake measured at different ages correlate positively. Finally, the fish in this study were fed with two different diets, having different protein and lipid content, to examine the consistency of phenotypic and genetic parameters across distinct nutritional environments. Feed intake of salmonids changes across nutritional environments [7], and in response to changes in body composition and mass, e.g. in the form of compensatory feeding [15]. Hence, it is possible that phenotypic and genetic parameters of feed intake differ on alternative diets. The two diets, a normal protein diet (NP) representing modern feeds, and an experimental high protein diet (HP), were established to specifically assess the influence of diets on phenotypic and genetic (co)variation of composition traits (detailed by Tobin et al., in prep.) but here the same experimental set up was applied for feed intake.

\section{MATERIALS AND METHODS}

\subsection{Population structure}

The fish used originated from the Finnish national breeding programme (The Selec), carried out at the Tervo Fisheries Research and Aquaculture station (a freshwater station) of the Finnish Game and Fisheries Research Institute. The initial population was established in the late 1980s by crossing four high quality strains. The broodstock management and selection procedures are described by Kause et al. [20]. The fish for the present study were kept in freshwater at the Tervo station during the whole experiment (June 2001 until November 2004).

In order to study the potential for selective breeding of feed intake, the 2001 generation was exposed to two different diet treatments in a split-family design. In April 2001, a total of 89 sires and 109 dams were mated in a factorial design to produce 210 full/half-sib family groups. Each sire was mated to an average 
Table I. Population structure and average family size for a total of 210 families sampled at three recording times.

\begin{tabular}{lll}
\hline & 165 families & 45 families \\
\hline Number of sires and dams & 81,99 & 34,40 \\
Family size, time 1 (1st X-Ray) & 6.6 & 30.9 \\
Family size, time 2 (2nd X-Ray) & 5.4 & 26.6 \\
Family size, time 3 (3rd X-Ray) & 4.4 & 13.4 \\
\hline
\end{tabular}

of 2.3 dams (range: $1-5$ ) and each dam to 1.9 sires (range: $1-3$ ). The matings lasted three days. The pedigree for every fish was known from the generations born in 1998, 1995, 1992 and 1989.

The eggs were incubated in the same incubator, but families were kept separated. The eye-staged eggs were transferred to indoor $150 \mathrm{~L}$ family tanks in June 2001. Each of the 210 family was held in their own tank.

In February 2002, after 8 months of growing in the family tanks, 2931 fingerlings were removed from the tanks and individually tagged with PIT-transponders (Trovan Ltd, Germany) to enable individual identification. For 165 of the 210 families, an average of 7.0 fish per family were tagged (range 4-7 fish). From the remaining 45 families, an average of 39.6 fish per family (range 37-40 fish) were tagged. The large initial family size was chosen because these families were destructively sampled for muscle and body composition for other purposes than this study. The change in the average family size across the three sampling times is shown in Table I. Before the initiation of the diet treatments, all fish were fed with commercial rainbow trout dry feed (Nutra Starter and Nutra Parr, Rehuraisio Inc., Finland).

\subsection{Fish management}

During tagging, fish from each family were split into two groups to be reared on different diets. In May 2002 (week 20) two dietary treatments were initiated. The diets were a modern diet with normal protein (40-45\%) and high lipid content (30-33\%) (NP diet), and an alternative diet with high protein (50-56\%) and low lipid content (15-24\%) (HP diet) (Tab. II). The diets consisted of fish meal, fish oil, wheat meal and wheat starch, and were supplemented for minerals and vitamins according to the NRC, National Research Council [31]. The experimental HP diet was designed so that the capacity of inefficient fish to deposit digested protein as protein growth would be greatly exceeded, leading to their slower growth and higher lipid deposition compared to the efficiency of individuals. This was hypothesised to lead to an enhanced selection potential 
Feed intake in fish breeding

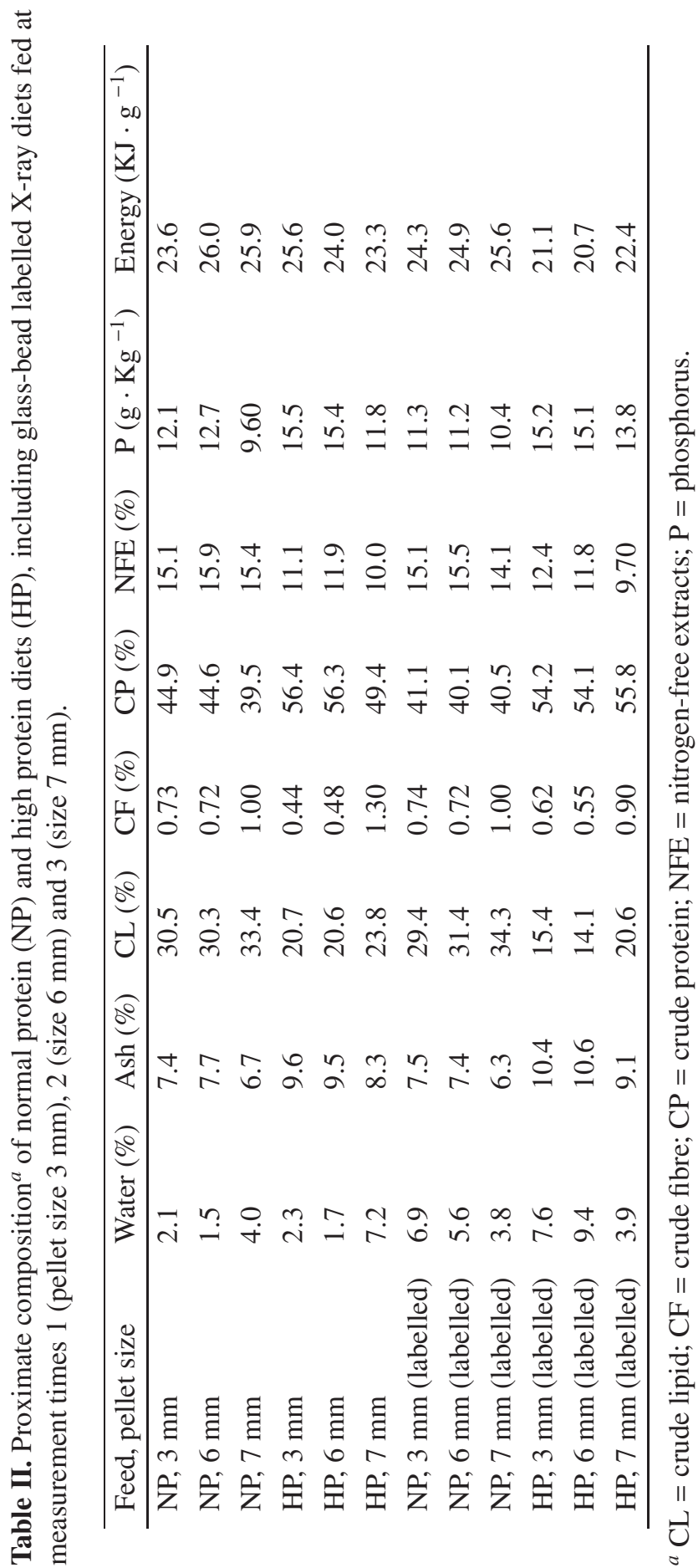


on the HP diet, in terms of increased heritabilities of lipid body composition and more favourable correlations between growth and lipid deposition (Tobin et al., in prep.).

The fish split between the two diets were of similar mass at tagging (mean \pm $\mathrm{SD}: \mathrm{NP}=62.4 \pm 19.9 \mathrm{~g}, n=1355$ and $\mathrm{HP}=62.3 \pm 19.4 \mathrm{~g}, n=1335)$. Each diet group was placed in four replicate fibreglass test tanks and housed indoors. Fish were kept in $3 \mathrm{~m}^{3}$ tanks until week 24 and transferred to $20 \mathrm{~m}^{3}$ tanks thereafter. The families were equally distributed among the tanks. Fish density in each tank remained under $20 \mathrm{~kg} \cdot \mathrm{m}^{-3}$.

Feeding was automated using computer-controlled pneumatic feeders (Arvo-Tec Inc., Finland). Daily feeding ration was based on continuous temperature measurements and the growth formula for rainbow trout based on an optimum growth temperature of $16{ }^{\circ} \mathrm{C}$. Slight overfeeding with 10-20\% feed given over the recommendations was applied during the experiment to prevent a restriction of growth potential of the fish. Water temperature during the experiment was ambient and exposed to seasonal fluctuations (range = $0.4-22.9^{\circ} \mathrm{C}$ ). Oxygen concentration was kept over $6.0 \mathrm{mg} \cdot \mathrm{L}^{-1}$ and a constant photoperiod of 16L:8 D was used.

\subsection{Recording traits}

Daily feed intake and body mass were recorded on three occasions; May 2002 (time 1, at $140 \mathrm{~g}$ ), October 2002 (time 2, at $750 \mathrm{~g}$ ), and September 2003 (time 3, at $2000 \mathrm{~g}$ ). The timing of a trait recording is indicated by a subscript of the trait name. The results for body mass are briefly summarised here to compare the feed intake results with a trait for which behaviour is already well understood and documented [19,20].

Each recording time, 1, 2 and 3, consisted of a 3-week session with three repeated weekly measurements of both body mass and daily feed intake. During a 3-week session, each tank was measured once a week, measuring two tanks per day in a consistent order each week. Due to the measurement constraints for feed intake trials, the test tanks were divided into two feeding groups (two NP and two HP tanks per group), one group being fed from 0400 to $0800 \mathrm{~h}$ and the other group from 0800 to $1200 \mathrm{~h}$. On successive days the recording order of NP and HP tanks was reversed, to avoid the effects of systematic feeding rhythms. In other words, on Tuesday mornings one NP and one HP tank were measured successively, on Wednesday mornings one HP and one

NP tank were measured successively, etc. To initiate a session, all fish were weighed during the first week of each session, and predetermined randomly 
chosen fish from each family were recorded for feed intake using the X-ray method. During the second and the third weeks, only the fish X-rayed during the first week were weighed and X-rayed again.

The X-rays were performed in the same way for all tanks and during all sessions. Individual feed intake was recorded by X-radiography using a portable X-ray unit (Todd Research 80/20, UK), as described by Talbot and Higgins [38] and McCarthy et al. [30]. Prior to X-ray, all fish from a given tank were fed as usual but the diet was labelled with radio-opaque ballotini glass beads (Jencons Scientific Ltd, Leighton Buzzard, UK) (Tab. II). The labelled pellets used at times 1, 2 and 3 consisted of $1 \%, 0.5 \%$ and $0.3 \%$ beads with a diameter of $400-600 \mu \mathrm{m}$, respectively (i.e. $43-45$ beads $\cdot \mathrm{g}^{-1}$ of dry feed at time $1,12-17$ beads $\cdot \mathrm{g}^{-1}$ of dry feed at time $2,7-12$ beads $\cdot \mathrm{g}^{-1}$ of dry feed at time 3). A minimum of $2 \mathrm{~h}$ after the feeders had stopped providing feed, the fish to be recorded were serially placed into anaesthetic solution (buffered MS-222), weighed and X-rayed. After X-raying, the fish were returned to their respective tanks. Thereafter, the beads were counted from the films, and the mass of feed within a stomach was estimated using a calibration regression equation. A calibration line was constructed for each session and each diet separately. This was done by X-raying different but known amounts of feed ( $n=$ minimum of 8 feed samples per diet), and then by regressing the number of beads counted against the known feed mass $\left(R^{2}=0.90-0.99\right)$. Moreover, separate experiments were performed to find an appropriate duration for the feeding period and for the timing of the X-rays to avoid evacuation of the feed with beads before X-raying the fish (data not shown).

The fish were recorded for sex and maturity in May 2003 through visual inspection of secondary sexual characters, and in November 2003 by the examination of gonads from slaughtered fish. The fish were classified into six sex/maturity groups; males were classified as mature at 2, 3, or later years, females as mature at 3 or later years, and all other fish as individuals of unknown sex and maturity age.

\subsection{Repeatability and accuracy of records}

Repeatabilities were calculated to establish the consistency of daily feed intake records in each diet and each three-week X-ray session. When repeated records for each individual are available, phenotypic variance $\left(V_{P}\right)$ is composed of $V_{P}=V_{G}+V_{E g}+V_{E s}$, where $V_{G}$ refers to genetic variance, $V_{E g}$ to general environment variance, and $V_{E s}$ to the within-individual variance arising from repeated measurements. Repeatability was calculated as 
$r=1-V_{E s} / V_{P}$ [9] and its standard error as described by Becker [3]. The accuracy of observations is increased by calculating the mean of $n$ repeated records measured for each individual. This reduces $V_{E s}$ by a factor of $1 / n$ and consequently reduces the phenotypic variance of the mean values $\left(V_{\text {mean }}\right)$. Thus, the ratio of $V_{\text {mean }}$ to $V_{P}$ is a measure of a gain in the accuracy from repeated records. The change in accuracy (in units of $\%$ ) was calculated as $100-100[1+r(n-1)] / n$ [9]. Furthermore, a repeatability of the mean of $n$ repeated records was calculated as $r_{\text {mean }}=n r /[1+(n-1) r]$.

\subsection{Least squares means}

The fish were recorded for body mass and daily feed intake one to three times during each 3-week X-ray session. Because some fish lacked one or two of the three records and because there were differences among the average weekly trait means, the raw means for each individual would have been unsuitable for the subsequent calculations. Therefore, weighted least squares means for each individual were obtained by accounting for the test tank-wise weekly performance. This was performed for each tank separately by fitting an analysis of variance to the longitudinal feed intake data with a model including individual fish (all fish within a given test tank) and test week (weeks 1,2 , and 3) as factors, and calculating least squares means for each individual (LSMeans option, SAS ${ }^{\circledR}$ Software, Cary, NC). These weighted means for the individuals were used as observations in the subsequent statistical and genetic analyses.

\subsection{Statistical tests for diet differences}

In order to examine the differences between the diets in body mass and feed intake, parametric analyses of variance were performed on the least squares means of individual records (procedure Proc Mixed, SAS ${ }^{\circledR}$ Software). The fixed effects included in the model were diet, sex/maturity class, and interaction of diet with sex/maturity. The random factors included were family (this consists of both common environment effect and genetic effect of the 210 families), test tank nested within diet, interaction of family with diet, interaction of family with sex/maturity class, and interaction of test tank with sex/maturity. Test tank was considered to be a random factor in the Anova to be able to generalise the results to include other test environments. The method of Kenward and Roger [22] was used to calculate correct $F$-tests and their degrees of freedom for the fixed effects. Average feed intakes were square root-transformed to 
obtain normally distributed residuals for the models. When calculating statistical tests and least squares means for relative feed intake (average feed intake corrected for body mass), body mass was included as a covariate in the models of average feed intake. This trait is here referred as feed intake $\%$.

\subsection{Genetic analyses}

(Co)variance components were estimated from the least-squares means of individual records using average information (AI) restricted maximum likelihood method of the DMU software [13].

A trait measured on the two diets was regarded as two different traits. The model for the diet-specific feed intakes and body mass was the following:

$$
y_{i j k l}=\operatorname{anim}_{i}+\operatorname{famtank}_{j}+\operatorname{SEXMAT}{ }_{k}+\text { TESTTANK }_{l}+\varepsilon_{i j k l},
$$

where $\operatorname{anim}_{i}$ is a random genetic effect of an animal $(i=1 \ldots$ number of obser-

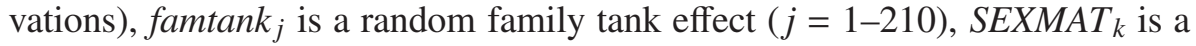
fixed sex and maturity effect $(k=1-6), T_{E S T T A N K_{l}}$ is a fixed test tank effect ( $l=1-4$ tanks), $\varepsilon_{i j k l}$ is the residual, and $y_{i j k l}$ is an observation of an individual. Test tank is considered to be a fixed factor in the genetic analysis because we want to remove its effect on phenotypic variance and because of the low number of test tanks. For feed intakes recorded at times 2 and 3, the random family tank effect was negligible, and it was removed from the model. To calculate genetic parameters for relative feed intake (feed intake \%), body mass was included as a covariate to the models of average feed intake.

Using these models, genetic $\left(V_{G}\right)$, common environment $\left(V_{\text {famtank }}\right)$, residual $\left(V_{R}\right)$ and phenotypic variances $\left(V_{P}=V_{G}+V_{R}+V_{\text {famtank }}\right)$, as well as phenotypic $\left(r_{P}\right)$ and genetic correlations between traits $\left(r_{G}\right)$ were obtained. Heritability was calculated as $h^{2}=V_{G} / V_{P}$ and common environment ratio as $c^{2}=V_{\text {famtank }} / V_{P}$. Common environment (co)variance includes effects due to separate rearing of full-sib families until tagging, but also parts of dominance effects. Genetic (co)variances, estimated by the animal effect, include additive genetic (co)variance but also parts of dominance (co)variance. Consequently, the statistical model used does not allow us to get a clean (isolated) estimate for the additive genetic (co)variances. Rather, genetic variances, heritabilities and genetic correlations estimated here are broad-sense estimates. To scale the phenotypic variance of traits with different means $(\bar{x})$, coefficient of phenotypic variation was calculated as $C V_{P}=\sqrt{V_{P}} / \bar{x}$. Approximate standard errors of (co)variances were obtained by a first-order Taylor series expansion of the AI matrix of the estimated (co)variances [13]. The standard errors of heritabilities, genetic correlations, and $C V$ were calculated following Becker [3]. 
Table III. Repeatabilities ( \pm their standard errors) for daily feed intake and body mass during the three recording times.

\begin{tabular}{clll}
\hline & Time 1 & Time 2 & Time 3 \\
\hline Normal Protein: & & & \\
Feed intake & $0.10 \pm 0.027$ & $0.09 \pm 0.030$ & $0.15 \pm 0.032$ \\
Body mass & $0.71 \pm 0.016$ & $0.96 \pm 0.003$ & $0.92 \pm 0.006$ \\
& & & \\
High Protein: & & & \\
Feed intake & $0.28 \pm 0.026$ & $0.22 \pm 0.027$ & $0.32 \pm 0.031$ \\
Body mass & $0.69 \pm 0.017$ & $0.96 \pm 0.003$ & $0.91 \pm 0.006$ \\
\hline
\end{tabular}

\section{RESULTS}

\subsection{Repeatability and accuracy of feed intake records}

Repeatabilities for daily feed intake recorded during a 3-week period were low to moderate ( 0.09 to 0.32 ). The values were higher for the HP diet, and two times the standard errors did not overlap between the diets (Tab. III). Body mass displayed high repeatabilities, ranging from 0.69 to 0.96 . There was no difference between the diets in the repeatabilities of body weight. These results indicate considerable amounts of measurement noise for repeated daily feed intake measurements, but clearly less for body mass measurements.

For feed intake with average repeatabilities of $0.1-0.3$ on the two diets, the measurement accuracy was increased drastically when the number of repeated measurements was increased from one to three (Fig. 1). When repeated measurements exceeded three, the increase in accuracy diminished. For traits with repeatabilities of 0.1 and 0.3 for individual records, the repeatabilities for the mean of the three repeated records $\left(r_{\text {mean }}\right)$ were increased to 0.25 and 0.56 , respectively, proving the usefulness of pooling the repeated records. Increasing the number of repeated individual records to six increased the $r_{\text {mean }}$ values further to 0.40 and 0.72 . These results confirmed that at least three measurements were needed to provide a good estimate of average feed intake, although, a better estimate was gained with 4-6 measurements.

As expected, for body mass with an average repeatability of 0.9 , the measurement accuracy was only marginally improved by increasing the number of measurements (Fig. 1). 


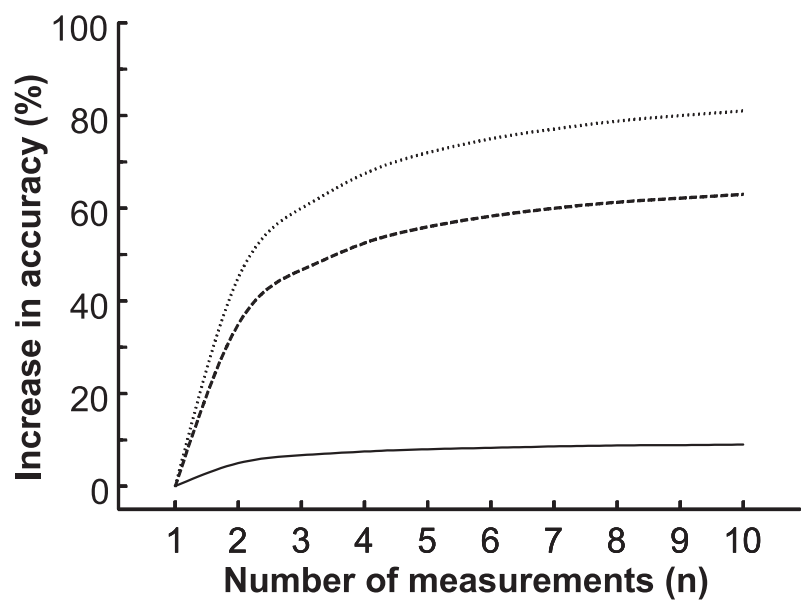

Figure 1. An increase in measurement accuracy ( $y$-axis) as a function of the number of repeated measurements ( $x$-axis) for traits with different repeatabilities. Repeatabilities of 0.1 (dotted line) and 0.3 (dashed line) represent daily feed intake, and repeatability of 0.9 (solid line) body mass.

\subsection{Effect of diet on feed consumption}

The comparison of the diet means of average feed intake showed that fish fed the HP diet had higher feed consumption compared to fish fed the NP diet (Tab. IV). Fish fed the HP diet consumed 15.6-39.3\% more than the NP fish, the difference being statistically significant in two out of three sampling times. When corrected to common body mass using body mass as a covariate, the higher feed intake \% on the HP fish was maintained or even elevated and the diet difference was statistically significant in all three sampling times (25.6-37.7\% difference, Tab. IV). None of the body mass traits differed significantly between the diets (Tab. IV).

\subsection{Genetic and phenotypic variation in feed intake}

Coefficients of phenotypic variation $\left(C V_{p}\right)$ for average feed intake were high, ranging from 29.9 to 59.3 (Tab. V). Standard errors of $C V$ were large, and they indicated non-significant differences between the diets. This occurred regardless of the fact that at time $1, C V_{p}$ for feed intake was 1.25 times higher with the NP diet. At times 2 and 3, $C V_{p}$ was 1.3-1.4 times higher with the HP diet than with the NP diet. The same trend was evident for feed intake \% (Tab. V). 
A. Kause et al.

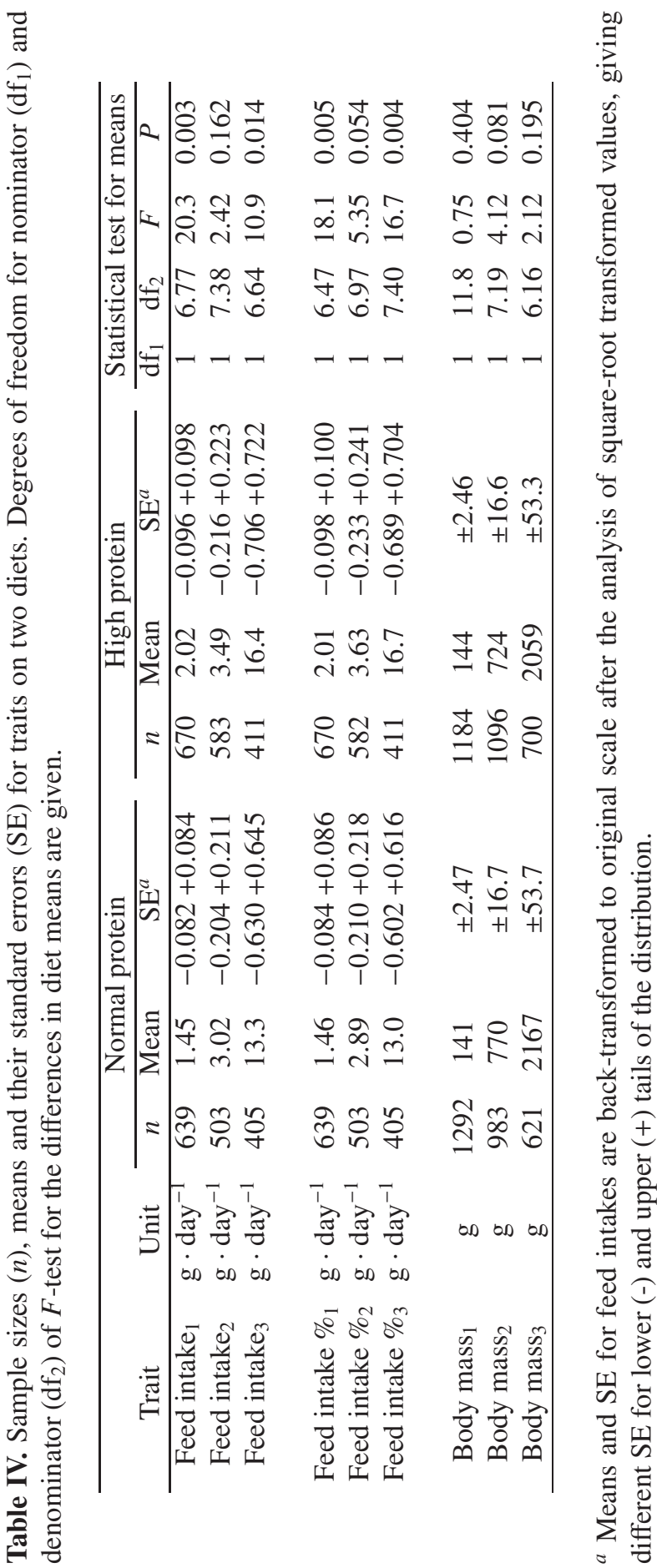


Table V. Variances $\left(V_{P}\right)$, coefficients of phenotypic variation $\left(C V_{p}\right)$, heritabilities $\left(h^{2}\right)$, common environment ratios $\left(c^{2}\right)$ and their standard errors (SE) for traits recorded on fish reared with two diets.

\begin{tabular}{|c|c|c|c|c|c|c|c|}
\hline & $V_{p}$ & $C V_{p}$ & SE & $h^{2}$ & $\mathrm{SE}$ & $c^{2}$ & $\mathrm{SE}$ \\
\hline \multicolumn{8}{|l|}{ Normal protein: } \\
\hline Feed intake ${ }_{1}$ & 0.295 & 37.5 & 9.11 & 0.03 & 0.06 & 0.15 & 0.06 \\
\hline Feed intake $_{2}$ & 2.08 & 44.5 & 11.5 & 0.17 & 0.10 & - & - \\
\hline Feed intake $_{3}$ & 33.5 & 41.1 & 11.0 & 0.02 & 0.07 & - & - \\
\hline Feed intake $\% 1$ & 0.202 & 31.1 & 7.62 & 0.14 & 0.09 & 0.06 & 0.05 \\
\hline Feed intake $\%_{2}$ & 1.60 & 39.0 & 9.91 & 0.09 & 0.07 & - & - \\
\hline Feed intake $\%_{3}$ & 25.8 & 36.1 & 9.69 & 0.06 & 0.08 & - & - \\
\hline \multicolumn{8}{|l|}{ High protein: } \\
\hline Feed intake 1 & 0.383 & 29.9 & 7.40 & 0.14 & 0.10 & 0.18 & 0.07 \\
\hline Feed intake $_{2}$ & 5.07 & 59.3 & 14.5 & 0.06 & 0.07 & - & - \\
\hline Feed intake $_{3}$ & 112 & 58.5 & 15.9 & 0.19 & 0.11 & - & - \\
\hline Feed intake $\%_{1}$ & 0.182 & 20.6 & 4.92 & 0.17 & 0.10 & 0.06 & 0.05 \\
\hline Feed intake $\%_{2}$ & 4.62 & 56.6 & 13.8 & 0.05 & 0.06 & - & - \\
\hline Feed intake $\%_{3}$ & 110 & 58.0 & 15.5 & 0.00 & 0.05 & - & - \\
\hline
\end{tabular}

Heritabilities for average feed intake were low and no large differences were found between the diets (Tab. V). Heritabilities for feed intake were on average 0.07 with NP and 0.13 with the HP diet, indicating a modest genetic potential for selective breeding. In two out of the three cases (time 1 and 3), the heritabilities were higher with the HP diet, yet with largely overlapping confidence limits. For feed intake $\%$ the heritabilities were on average 0.10 with NP and 0.07 with HP (Tab. V).

The average heritabilities for body mass with the NP (0.22) and HP diet (0.27) were higher than for feed intake (detailed results not shown).

\subsection{Consistency of ranking between ages}

For average feed intake of fish fed the NP diet, phenotypic $\left(r_{P} \geq 0.18\right)$ and genetic correlations $\left(r_{A} \geq 0.63\right)$ between successive times (fish ages) were moderate-to-high (Tab. VI). In contrast, phenotypic and genetic correlations between the first and the last feed intake records were close to zero. For fish fed the HP diet, only phenotypic and genetic correlations between times 1 and 2 were moderate-to-high, while the other correlations were low or even 
Table VI. Phenotypic (above diagonal) and genetic correlations \pm SE (below diagonal) between different ages for daily feed intake.

\begin{tabular}{|c|c|c|c|}
\hline & Feed intake ${ }_{1}$ & Feed intake 2 & Feed intake ${ }_{3}$ \\
\hline \multicolumn{4}{|l|}{ Normal protein: } \\
\hline Feed intake ${ }_{1}$ & - & 0.20 & 0.03 \\
\hline Feed intake $_{2}$ & $0.63 \pm 0.50$ & - & 0.18 \\
\hline Feed intake $_{3}$ & $0.08 \pm 0.77$ & $0.82 \pm 0.43$ & $\bullet$ \\
\hline \multicolumn{4}{|l|}{ High protein: } \\
\hline Feed intake ${ }_{1}$ & $\bullet$ & 0.22 & 0.00 \\
\hline Feed intake $_{2}$ & $0.89 \pm 0.40$ & - & 0.11 \\
\hline Feed intake $_{3}$ & $-0.37 \pm 0.32$ & $-0.12 \pm 0.55$ & $\bullet$ \\
\hline Normal protein: & Feed intake $\%_{1}$ & Feed intake $\%_{2}$ & Feed intake $\%_{3}$ \\
\hline Feed intake $\%_{1}$ & - & -0.08 & -0.09 \\
\hline Feed intake $\%_{2}$ & $-0.66 \pm 0.46$ & - & 0.05 \\
\hline Feed intake $\%_{3}$ & $-0.61 \pm 0.52$ & $0.60 \pm 0.72$ & $\bullet$ \\
\hline \multicolumn{4}{|l|}{ High protein: } \\
\hline Feed intake $\%_{1}$ & - & 0.05 & 0.00 \\
\hline Feed intake $\%_{2}$ & $0.66 \pm 0.49$ & $\bullet$ & 0.14 \\
\hline Feed intake $\%_{3}$ & ne & ne & - \\
\hline
\end{tabular}

ne: non-estimable due to low heritability.

negative. For feed intake $\%$, the phenotypic and genetic correlations were decreased compared to the correlations for the raw feed intake records (Tab. VI). Due to the low heritabilities, standard errors of all the genetic correlation for average feed intake were high, preventing reliable interpretation and betweendiet comparisons.

For body mass, both phenotypic (average $r_{P}=0.61$ ) and genetic correlations (average $r_{G}=0.73$ ) between ages were clearly higher than for average feed intake (detailed results for mass not shown). The lower correlations between ages for average feed intake compared to body mass indicate that some favourable correlated responses are expected to occur when selecting on feed intake at one time point, yet the predicting power is lower than for body masses.

\section{DISCUSSION}

Feed intake is a fundamental component of feed efficiency, and thus, an attractive trait for fish breeders. We show here that both recording and breeding 
for feed intake were more challenging than for body mass. Yet, sufficient genetic variation exists that allows selective breeding of feed intake. However, this is contingent on accurate feed intake estimates that arise through repeated observations at several life stages.

\subsection{Recording feed intake}

Repeatabilities for point estimates of daily feed intake were modest (0.09-0.32), showing that the single daily feed intake observations were only weakly correlated. This was in strong contrast with the high repeatability of body mass $(r \geq 0.69$ ). Body size and morphological traits typically show high repeatabilities, whereas behavioural and reproduction traits show lower ones $[9,27]$. The coefficient of variation for average feed intake was unexpectedly high compared to $C V$ of morphological traits such as body mass. The low repeatability and the high variability for feed intake is likely to result from biological factors. Feed intake of individual fish varies greatly from dayto-day $[15,28,39]$, and thus, a single daily measurement does not accurately describe average feed intake for a single life stage in rainbow trout. Similarly, Jobling and Koskela [15] showed that in rainbow trout the correlations of feed intake records between sampling days separated by four days ranged between $0.12-0.80$.

The analysis of measurement accuracy revealed that at least three daily feed intake measurements were needed for an accurate estimation of average feed intake. Already Jobling et al. [16] concluded that when using the $\mathrm{X}$-ray method, repeated feed intake records are needed to increase recording accuracy, but no quantitative approaches have been used so far to assess the number of daily records needed. Previous studies using the X-ray method to examine individual variation in feed intake have typically recorded feed intake during 1-5 days e.g. [14-16, 28, 29, 36]. However, considerably longer testing periods have been used when feed intake has been recorded as mean consumption of a group of fish held in a common tank. Genetic studies based on such a method have lasted 21-70 days and feed intake has been recorded either as the difference between feed given and feed waste collected from a given tank, or as oxygen consumption within a tank $[23,25,40]$. The longer testing period is a result of the fact that detailed individual-level data is more challenging to record compared to tank-level data.

It should be noted that here the aim was to record long-term feed intake, covering a period of three weeks at a fixed age, and ultimately, the whole production time of large rainbow trout. Although the X-ray method exhibits 
considerable recording noise for the long-term feed intake, the method is still accurate for the purposes of short-term physiological and behavioural studies lasting a few days. It is well established that the X-ray method accurately describes the true daily feed intake $[28,30]$.

It would be beneficial to obtain higher repeatabilities for feed intake, e.g. using improved recording methods, or by recording feed intake throughout on-growing, as is done in farm animals. A trace element method in which a marker included in feed accumulates in the fish body has been used in fish and may prove to be a useful alternative to record intake for longer periods of time e.g. $[10,24]$. In farm animals, average daily feed intake is typically recorded during each day of a long testing period, in some cases over the whole production time (e.g., in pigs). For instance, the testing period has been 35-100 days for pigs [33,35], 70-119 days for cattle [1,2], 42-56 for lambs [4, 11,37], and 23-182 days for chicken [5,34]. In comparison, in the present study feed intake was recorded at each age only during three days, yet over a 21-day testing period. Archer et al. [1] showed how error variance is dramatically decreased when the testing period is prolonged from 7 days to 119 days in cattle. An improved feed intake recording in fish would lead to more reliable estimates for treatment means, individual feed intakes, genetic parameters, a reduced need for several repeated records, and an increased power of statistical tests due to reduced error variance.

Phenotypic and genetic correlations between average feed intakes recorded at different ages were only moderate. The highest correlations were between successive ages, indicating that some favourable correlated genetic responses are expected when selecting only for one trait. If average feed intake is to be recorded at a single occasion, then market-sized fish (>750 g) should be preferred. This is because early measurements taken from $140 \mathrm{~g}$ fish cannot be used as reliable predictors over the whole growing period. The results show further that if one attempts to effectively breed for long-term feed intake, several records are needed from fish of different ages. In line with our finding on the re-ranking of families across ages, Thodesen et al. [39] showed that relative feed intake of selectively bred Atlantic salmon is higher than that of wild salmon only during the early stages of growth (when grown from $814 \mathrm{~g}$ to $1455 \mathrm{~g}$ ), revealing a strain-by-age interaction.

\subsection{Heritability for feed intake}

The heritability for average feed intake was low (average $h^{2}=0.10$ ), the highest individual value being 0.17. Consequently, there is sufficient 
genetic variation to be used for selective breeding, but clearly less than for body mass [19, this study]. Heritabilities for feed intake in poultry (average 0.45 , [32]), pigs $(0.29,[6])$, sheep (average $0.36,[4,11,37]$ ), and cattle (average $0.41,[26]$ ) are higher than reported here, probably reflecting the fact that feed intake displays less unexplained residual variation and feed intake records are more reliable in farm animals.

With the exception of Silverstein et al. [36], previous studies on the genetics of feed intake in fish have been based on family mean records. Each full-sib family has been kept in their own (or replicated) tanks, and the tankmean feed intake has been recorded. As stressed by Doupé and Lymbery [8], the drawback of this approach is that by calculating the family means, the great within-family variation existing in fish is excluded from the data. Heritabilities and proportion of variation due to family from such studies range from $0.31-0.84[23,25,40]$ but these are overestimates due to the family mean method. Silverstein et al. [36] found a heritability of $0.37-0.41$ for individual feed intake records of catfish. The higher heritability compared to the present study may be due to species difference or differences in experimental design. For instance, Silverstein et al. used a full-sib design in which case environmental effects common to full sibs tend to raise heritability estimates.

In pigs, at the early stages of growth when pigs mainly deposit protein, low feed intake may be restricting their growth. In contrast, as pigs age, voluntary feed intake greatly exceeds energy requirements, and thus, reduces feed efficiency and increases lipid deposition [35,41]. Accordingly, the aim of genetically changing feed intake is not always to reduce it. In farm animals, random regression methods have been applied to simultaneously analyse all separate feed intake records over the whole life span, in order to control the genetic changes occurring at different ages [33,35]. Applying the random regression method for individual daily records appears difficult in salmonids. This is due to the high day-to-day variability of feed intake, in which case, for example, feed intake of some individuals has negative regression slopes even though these individuals are growing steadily during a test period.

\subsection{Diet effects on feed consumption and repeatabilities}

Fish on the HP diet had higher average feed consumption than fish on the NP diet with two, or more, explanations. First, fish fed the HP diet may be deficient in lipid or energy (and they are of smaller size) and there may have been an attempt to compensate for this by feeding more. It has previously been shown that fish actively compensate for reduced lipid stores and small body size by 
increasing feed and energy intake e.g. [17, 18]. Second, with the NP diet there was no requirement to increase feed intake to meet the extra protein demand associated with growth. This is because the excess lipid in the diet may fulfil energy requirements, thus allowing fish to spare protein for the purposes of growth, leading to a protein sparing effect [12]. Moreover, repeatabilities were higher with the HP diet. This may be a result of the higher overall consumption of that diet.

To conclude, the analyses of the daily feed intake data recorded using the $\mathrm{X}$-ray method proved that selection to genetically change long-term feed intake can be successful, yet repeated observations at several life stages are needed to ensure the accuracy of feed intake estimates and the efficiency of selection.

\section{ACKNOWLEDGEMENTS}

Tuija Paananen, Heli Wahlroos, Ángel Ruiz Bañón and César Luis Borreguero helped in data collection and preparation. Novalab Ltd. conducted the chemical analysis of the feeds. Rob Doupé and an anonymous referee provided helpful comments on the previous versions of the text. You are all greatly acknowledged. This work has been carried out with the financial support from the Commission of the European Communities, Quality of Life and Management of Living Resources Programme, project Q5RS-2001-0994 "Protein and Growth Efficiency in Salmonid Selection (PROGRESS)". It does not reflect its views and in no way anticipates the Commission's future policy in this area.

\section{REFERENCES}

[1] Archer J.A., Arthur P.F., Herd R.M., Parnell P.F., Pitchford W.S., Optimum postweaning test for measurement of growth rate, feed intake, and feed efficiency in British breed cattle, J. Anim. Sci. 75 (1997) 2024-2032.

[2] Arthur P.F., Archer J.A., Johnston D.J., Herd R.M., Richardson E.C., Parnell P.F., Genetic and phenotypic variance and covariance components for feed intake, feed efficiency, and other postweaning traits in Angus cattle, J. Anim. Sci. 79 (2001) 2805-2811.

[3] Becker W.A., Manual of Quantitative Genetics, Academic Enterprises, Pullman, 1985.

[4] Cammack K.M., Leymaster K.A., Jenkins T.G., Nielsen M.K., Estimates of genetic parameters for feed intake, feeding behavior, and daily gain in composite ram lambs, J. Anim. Sci. 83 (2005) 777-785.

[5] Chambers J.R., Wang L., McMillan I., Genetic variation of broiler feed consumption and efficiency corrected for differences in test body weights, Poultry Sci. 73 (1994) 1196-1203. 
[6] Clutter A.C., Brascamp E.W., Genetics of performance traits, in: Rothschild M.F., Ruvinsky A. (Eds.), The Genetics of the Pig, CAB International, Wallingford, 1998, pp. 427-462.

[7] de la Higuera M., Effects of nutritional factors and feed characteristics on feed intake, in: Houlihan D., Boujard T., Jobling M. (Eds.), Food Intake in Fish, Blackwell, Oxford, 2001, pp. 250-268.

[8] Doupé R.G., Lymbery A.J., Indicators of genetic variation for feed conversion efficiency in black bream, Aquac. Res. 35 (2004) 1305-1309.

[9] Falconer D.S., Mackay T.F.C., Introduction to Quantitative Genetics, Longman Group Ltd, Essex, 1996.

[10] Forseth T., Jonsson B., Næumann R., Ugedal O., Radioisotope method for estimating brown trout food consumption, Can. J. Fish. Aquat. Sci. 49 (1992) 1328-1335.

[11] François D., Bibé B., Brunel J.B., Weisbecker J.L., Ricard E., Genetic parameters of feeding traits in meat sheep, in: Proceedings of the 7th World Congress on Genetics Applied to Livestock Production, 19-23 August 2002, Montpellier, France, CD-ROM Communication No. 10-10.

[12] Grayton R.D., Beamish F.W.H., Effects of feeding frequency on food intake, growth and body composition of rainbow trout (Salmo gairdneri), Aquaculture 11 (1977) 159-172.

[13] Jensen J., Madsen P., A user's guide to DMU. A package for analyzing multivariate mixed models, Research Center Foulum, Danish Institute of Animal Science, Tjele, 2000.

[14] Jobling M., Baardvik B.M., The influence of environmental manipulations on inter- and intra-individual variation in food acquisition and growth performance of Arctic charr, Salvelinus alpinus, J. Fish Biol. 44 (1994) 1069-1087.

[15] Jobling M., Koskela J., Interindividual variations in feeding and growth in rainbow trout during restricted feeding and a subsequent period of compensatory growth, J. Fish Biol. 49 (1996) 658-667.

[16] Jobling M., Baardvik B.M., Jørgensen E.H., Investigation of food-growth relationships of Arctic charr, Salvelinus alpinus L., using radiography, Aquaculture 81 (1989) 367-372.

[17] Jobling M., Covès D., Damsgård B., Kristiansen H.R., Koskela J., Petursdottir T.E., Kadri S., Gudmundsson O., Techniques for measuring feed intake, in: Houlihan D., Boujard T., Jobling M. (Eds.), Food Intake in Fish, Blackwell, Oxford, 2001, pp. 49-87.

[18] Johansen S.J.S., Ekli M., Stangnes B., Jobling M., Weight gain and lipid deposition in Atlantic salmon, Salmo salar, during compensatory growth: evidence for lipostatic regulation?, Aquac. Res. 32 (2001) 963-974.

[19] Kause A., Ritola O., Paananen T., Mäntysaari E., Eskelinen U., Selection against early maturity in large rainbow trout Oncorhynchus mykiss: the quantitative genetics of sexual dimorphism and genotype-by-environment interactions, Aquaculture 228 (2003) 53-68.

[20] Kause A., Ritola O., Paananen T., Wahlroos H., Mäntysaari E.A., Genetic trends in growth, sexual maturity and skeletal deformations, and rate of inbreeding in a breeding programme for rainbow trout, Aquaculture 247 (2005) 177-187. 
[21] Kennedy B.W., van der Werf J.H.J., Meuwissen T.H.E., Genetic and statistical properties of residual feed intake, J. Anim. Sci. 71 (1993) 3239-3250.

[22] Kenward M.G., Roger J.H., Small sample inference for fixed effects from restricted maximum likelihood, Biometrics 53 (1997) 983-997.

[23] Kinghorn B., Genetic variation in food conversion efficiency and growth in rainbow trout, Aquaculture 32 (1983) 141-155.

[24] Kolehmainen S.E., Daily feeding rates of bluegill (Lepomis macrochirus) determined by a refined radioisotopic method, J. Fish. Res. Board Can. 31 (1974) $67-74$.

[25] Kolstad K., Grisdale-Helland B., Gjerde B., Family differences in feed efficiency in Atlantic salmon (Salmo salar), Aquaculture 241 (2004) 169-177.

[26] Koots K.R., Gibson J.P., Smith C., Wilton J.W., Analyses of published genetic parameter estimates for beef production traits. 1. Heritability, Anim. Breed. Abstr. 62 (1994) 309-338.

[27] Lynch M., Walsh B., Genetics and Analysis of Quantitative Traits, Sinauer Associates, Sunderland, 1998.

[28] McCarthy I.D., Carter C.G., Houlihan D.F., The effect of feeding hierarchy on individual variability in daily feeding of rainbow trout, Oncorhynchus mykiss (Walbaum), J. Fish Biol. 41 (1992) 257-263.

[29] McCarthy I.D., Houlihan D.F., Carter C.G., Moutou K., Variation in individual consumption rates of fish and its implications for the study of fish nutrition and physiology, P. Nutr. Soc. 52 (1993) 427-436.

[30] McCarthy I.D., Houlihan D.F., Carter C.G., Individual variation in protein turnover and growth efficiency in rainbow trout, Oncorhynchus mykiss. P. Roy. Soc. Lond. B Bio. 257 (1994) 141-147.

[31] NRC National Research Council, Nutrient Requirements of Fish, National Academic Press, Washington DC, 1993.

[32] Pym R.A.E., Nutritional genetics, in: Crawford R.D. (Ed.), Poultry Genetics and Breeding, Elsevier, New York, 1990, pp. 847-876.

[33] Schnyder U., Hofer A., Labroue F., Künzi N., Multiple trait model combining random regressions for daily feed intake with single measured performance traits of growing pigs, Genet. Sel. Evol. 34 (2002) 61-81.

[34] Schulman N., Tuiskula-Haavisto M., Siitonen L., Mäntysaari E.A., Genetic variation of residual feed consumption in a selected Finnish egg-layer population, Poultry Sci. 73 (1994) 1479-1484.

[35] Schulze V., Roche R., Lorenzo Bermejo J., Looft H., Kalm E., Genetic associations between observed feed intake measurements during growth, feed intake curve parameters and growing-finishing performances of central tested boars, Livest. Prod. Sci. 73 (2002) 199-211.

[36] Silverstein J.T., Bosworth B.G., Waldbieser G.C., Wolters W.R., Feed intake in channel cat fish: is there a genetic component?, Aquac. Res. 32 (2001) 199-205.

[37] Snowder G.D., Van Vleck L.D., Estimates of genetic parameters and selection strategies to improve the economic efficiency of postweaning growth in lambs, J. Anim. Sci. 81 (2003) 2704-2713.

[38] Talbot C., Higgins P.J., A radiographic method for feeding studies on fish using metallic iron powder as marker, J. Fish Biol. 23 (1983) 211-220. 
[39] Thodesen J., Grisdale-Helland B., Helland S.J., Gjerde B., Feed intake, growth and feed utilization of offspring from wild and selected Atlantic salmon (Salmo salar), Aquaculture 180 (1999) 237-246.

[40] Thodesen J., Gjerde B., Grisdale-Helland B., Storebakken T., Genetic variation in feed intake, growth and feed utilization in Atlantic salmon (Salmo salar), Aquaculture 194 (2001) 273-281.

[41] Whittemore C.T., Tullis J.B., Emmans G.C., Protein growth in pigs, Anim. Prod. 46 (1988) 437-445.

To access this journal online: www.edpsciences.org 